\title{
Decreased Medical Care During the COVID-19 Pandemic - A Comprehensive Analysis of Radiological Examinations
}

\section{Veränderungen der medizinischen Versorgung während der COVID-19- Pandemie - eine umfassende Analyse radiologischer Untersuchungen}

Authors

Florian Nima Fleckenstein ${ }^{1}$, Tazio Maleitzke ${ }^{1}$, Georg Böning ${ }^{2}$, Johannes Kahn² ${ }^{\circledR}$ Laura Büttner ${ }^{2}$, Bernhard Gebauer², Annette Aigner ${ }^{*}$, Bernd Hamm²*

Affiliations

1 Berlin Institute of Health, BIH, Berlin, Germany

2 Department of Radiology, Charité-Universitätsmedizin Berlin, Germany

Key words

healthcare, shutdown, SARS-CoV-2, workload, economics lockdown

received 20.09.2020

accepted 12.01.2021

published online 18.03.2021

\section{Bibliography}

Fortschr Röntgenstr 2021; 193: 937-946

DOI 10.1055/a-1368-5047

ISSN 1438-9029

(C) 2021. Thieme. All rights reserved.

Georg Thieme Verlag KG, Rüdigerstraße 14,

70469 Stuttgart, Germany

\section{Correspondence}

Dr. Florian Nima Fleckenstein

Klinik für Radiologie, Charité-Universitätsmedizin Berlin,

Augustenburger Platz 1, 13353 Berlin, Germany

Tel.: + 49/30/450657 297

florian.fleckenstein@charite.de

\section{ZUSAMMENFASSUNG}

Ziele Radiologische Kliniken sind als Querschnittsfach in der Lage, wichtige Informationen über die Auswirkungen der COVID-19-Pandemie auf die Gesundheitsversorgung zu liefern. Ziel dieser Studie ist es, Veränderungen der medizinischen Versorgung während der ersten Pandemiewelle im Frühjahr 2020 mithilfe radiologischer Untersuchungen zu quantifizieren und mögliche zukünftige Mehrbelastungen zu ermitteln. Methoden Eine retrospektive Analyse aller radiologischen Untersuchungen während der ersten Pandemiewelle wurde mit entsprechenden Kontrollperioden aus den Vorjahren verglichen. Die Analyse erfasste dabei Veränderungen der medizinischen Versorgung innerhalb der Radiologie sowie differenziert nach

\footnotetext{
Both authors contributed equally to this work
}

medizinischen Fachgebieten. Die Anzahl nicht erfolgter Untersuchungen wurde außerdem extrapoliert, um eine potenzielle zukünftige Mehrbelastung bestimmen zu können.

Ergebnisse Insgesamt wurden 596760 Untersuchungen analysiert. Das Gesamtvolumen aller durchgeführten Untersuchungen verringerte sich während des Shutdowns im Vergleich zum Kontrollzeitraum um durchschnittlich $41 \%$. Die am stärksten betroffenen radiologischen Modalitäten waren Sonografie (-54\%), Röntgen ( $-47 \%)$, gefolgt von MRT (-42\%). Untersuchungszahlen der Unfallchirurgie und Orthopädie verzeichneten den stärksten Rückgang (-60\% Fallvolumen), gefolgt von der Allgemeinchirurgie (-49\%). Die Gesamtzahl der Untersuchungen stieg nach dem Shutdown wieder kontinuierlich an. In der Folge könnte das Untersuchungsvolumen in der Zukunft um bis zu 22 \% steigen.

Schlussfolgerungen Unsere Studie zeigt eine deutliche Abnahme der radiologischen Untersuchungen insgesamt und für einzelne medizinische Fachdisziplinen während der ersten Pandemiewelle im Frühjahr 2020.

\section{Kernaussagen:}

- Die Anzahl der radiologischen Untersuchungen nahm während der ersten Welle der COVID-19-Pandemie im Frühjahr 2020 um $41 \%$ ab.

- Für mehrere medizinische Fachdisziplinen wurde ein starker Rückgang der Fallzahlen um bis zu 60 \% ermittelt.

- Durch Extrapolation der nicht erfolgten Untersuchungen in die nahe Zukunft könnte die Arbeitsbelastung für radiologische Kliniken um bis zu 22 \% gegenüber den Vorjahreszahlen steigen.

\section{ABSTRACT}

Objectives As a cross-section discipline within the hospital infrastructure, radiological departments might be able to provide important information regarding the impact of the COVID-19 pandemic on healthcare. The goal of this study was to quantify changes in medical care during the first wave of the pandemic using radiological examinations as a comprehensive surrogate marker and to determine potential future workload.

Methods A retrospective analysis of all radiological examinations during the first wave of the pandemic was performed. The number of examinations was compared to time-matched 
control periods. Furthermore, an in-depth analysis of radiological examinations attributed to various medical specialties was conducted and postponed examinations were extrapolated to calculate additional workload in the near future.

Results A total of 596,760 examinations were analyzed. Overall case volumes decreased by an average of $41 \%$ during the shutdown compared to the control period. The most affected radiological modalities were sonography (-54\%), X-ray $(-47 \%)$ followed by MRI $(-42 \%)$. The most affected medical specialty was trauma and orthopedics ( $-60 \%$ case volume) followed by general surgery (-49\%). Examination numbers increased during the post-shutdown period leading to a predicted additional workload of up to $22 \%$.

Conclusion This study shows a marked decrease in radiological examinations in total and among several core medical specialties, indicating a significant reduction in medical care during the first COVID-19 shutdown.

\section{Key Points:}

- Number of radiological examinations decreased by $41 \%$ during the first wave of the COVID-19 pandemic.

- Several core medical specialties were heavily affected with a reduction of case volumes up to $60 \%$.

- When extrapolating postponed examinations to the near future, the overall workload for radiological departments might increase up to $22 \%$.

\section{Citation Format}

- Fleckenstein FN, Maleitzke T, Böning G et al. Decreased Medical Care During the COVID-19 Pandemic - A Comprehensive Analysis of Radiological Examinations. Fortschr Röntgenstr 2021; 193: 937-946

\begin{tabular}{|c|c|}
\hline \multicolumn{2}{|c|}{ ABBREVIATIONS } \\
\hline COVID-19 & novel coronavirus disease \\
\hline SARS-CoV-2 & $\begin{array}{l}\text { severe acute respiratory syndrome corona- } \\
\text { virus } 2\end{array}$ \\
\hline ICU & intensive care unit \\
\hline CTRL & control period 2018/19 \\
\hline PRECOV & pre-COVID disease period \\
\hline PREST & pre-shutdown transition period \\
\hline POST & post-shutdown period \\
\hline IRR & incidence rate ratio \\
\hline IQR & interquartile range \\
\hline SD & standard deviation \\
\hline LOESS & locally weighted scatterplot smoothing \\
\hline $\mathrm{Cl}$ & confidence interval \\
\hline
\end{tabular}

\section{Introduction}

The rapid spread of the novel coronavirus disease 2019 (COVID-19) [1], caused by the severe acute respiratory syndrome coronavirus 2 (SARS-CoV-2), was declared a global pandemic by the World Health Organization on March 3, 2020 [2]. Since then, worldwide shutdown measures were broadly implemented in order to contain the pandemic and to prevent a failure of healthcare infrastructures [3, 4].

The first confirmed SARS-CoV-2 infection in Germany was registered on January 27, 2020 and the first case in Berlin on March 2, 2020 [5]. Effective March 16, 2020, the German Federal Government requested that all clinics postpone all outpatient visits, non-viable hospital admissions, and therapeutic procedures, as well as increase intensive care unit (ICU) capacity in order to prepare for an unpredictable number of COVID-19 cases [6]. The shutdown was maintained for about one month until April 19. 2020. At the same time, steps were taken to financially support hospitals that reserved capacity for COVID-19 patients [7].
Data on the impact of the pandemic and the related executive measures on the healthcare system and especially on conditions other than COVID-19 are scarce and scattered [8-12]. While the second wave of the pandemic is ongoing, the lack of significant data means an unclear future for hospitals given the increasing clinical and economic pressure [13].

Diagnostic radiology has gained broad attention in the framework of COVID-19 diagnosis [14]. However, as a cross-section discipline within the hospital infrastructure, radiological departments can in fact provide important information regarding the overall quantity of medical care provided for patients [15].

This study aimed to analyze radiological examinations as a surrogate marker for changes in the amount of medical care provided during the first shutdown period in early 2020, compared to inter- and intra-year control periods. Furthermore, volume changes were assessed for relevant medical specialties to identify potential COVID-19 hotspots. Lastly, based on the analyzed data from one of the largest university hospitals in Europe, this study tries to determine the patient volume expected in the future in order to quantify surplus workload for the healthcare infrastructure.

\section{Methods}

We conducted a retrospective study involving all three campuses of the Charité Berlin, Germany. All included campuses are maximum-care hospitals. Patient-related examination data was anonymously extracted from the hospital's daily updated radiological electronic database for the study periods. This study was approved by the Local Ethics Committee and was conducted in accordance with the Declaration of Helsinki.

\section{Study Periods}

To assess the impact of the COVID-19 pandemic and executive measures related to it, we defined the relevant study periods as follows (chronologically): 
1. Inter-year 35-day control period for 2018 and 2019 (CTRL): time-matched to the shutdown period in 2020

2. Pre-pandemic control period (PRECOV): January 1 - March 2

3. Pre-shutdown transition control period (PREST): March 3 March 15

4. Shutdown study period: March 16 - April 19

5. Post-shutdown transition control period (POST): April 20 June 14

To visualize and analyze trends over time for both control years 2018 and 2019, we extracted all radiological examinations for these years from January 1 to June 15 .

\section{Data preparation}

We excluded clinically non-relevant imaging procedures including image duplicates, external images that were imported into our database, as well as test images. All examinations were classified according to their modality and medical specialty they were referred from, in order to assess changes in areas of interest. All examinations from outpatient centers and emergency rooms were coded as such for additional analyses. Furthermore, we also determined all radiological examinations linked to a suspected or confirmed SARS-CoV-2 infection.

Examinations were aggregated by day within the aforementioned time periods. For all patient-based analyses, patients were only counted once per analyzed time period.

Due to a clear effect of weekends on the number of examinations, we aligned all three years by calendar weeks. Therefore, the first observation of 2018 is January 3, 2019 starts with January 2, and data from June 15, 2020 was not used.

\section{Statistical Analysis}

We report absolute and relative frequencies for categorical variables, median along with the interquartile range (IQR) or mean along with standard deviation (SD) for continuous variables. We display the absolute number of radiological examinations by day over the full time periods for all three included years, also separately for regular shifts and weekends/holidays/night shifts and use a locally weighted scatterplot smoothing (LOESS) estimate to illustrate the smoothed trend over time. These analyses were also performed by medical specialty and for the median age and the ratio of men compared to women. Additionally, we graphically display the number of radiological examinations linked to suspected SARS-CoV-2 infections in 2020.

The number of examinations per day between periods was compared, thereby deriving the mean number of examinations per day along with $95 \%$ confidence intervals $(\mathrm{Cl})$, just as by negative binomial regression to correctly account for weekday, weekend, and holiday effects. For these analyses, the number of examinations per day from the reference years 2018 and 2019 was averaged.

In order to estimate the potential number of examinations only postponed and therefore performed in the near future, we extracted all outpatient examinations within PREST, Shutdown, and POST, and compared them to the same periods in 2018/19.

Statistical analyses were performed using R [16], just as additional R packages for data handling and plotting [17].

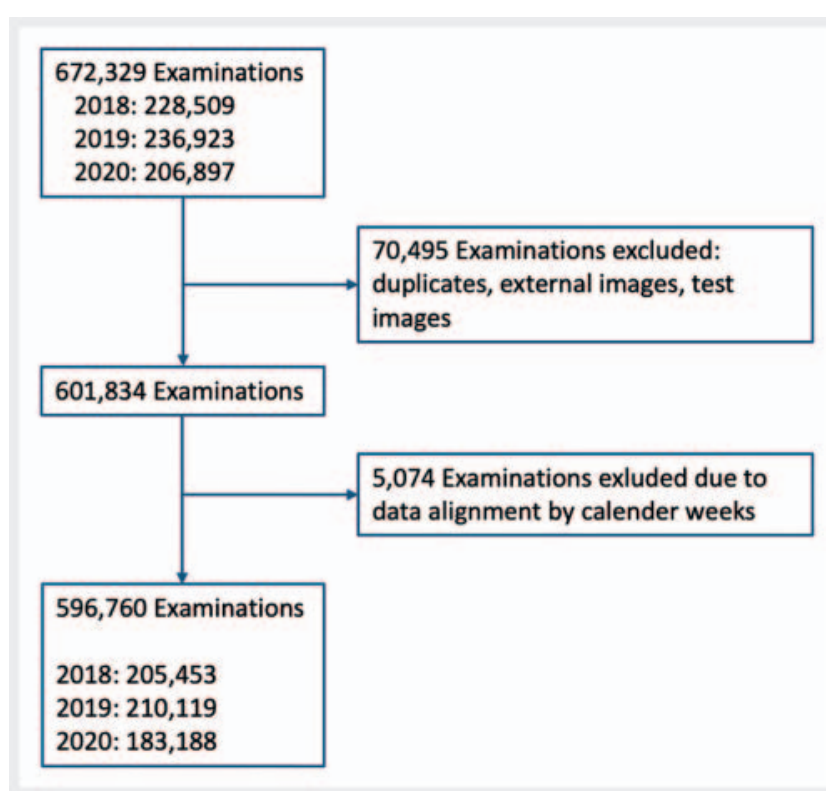

- Fig. 1 Flowchart of all radiological examinations included in the final analysis. A total of 70,495 cases were excluded due to clinically non-relevant imaging and alignment of the benchmark periods 2018/19 by calendar weeks.

- Abb. 1 Flussdiagramm aller in die endgültige Analyse einbezogenen radiologischen Untersuchungen. Insgesamt wurden 70495 Fälle ausgeschlossen.

\section{Results}

After excluding clinically non-relevant imaging and aligning our data by calendar weeks, a total of 596,760 examinations of 226,465 patients (median $=2$ examinations $(I Q R=1-4)$ ) were included in the final analyses ( $\nabla$ Fig. 1 ). The proportion of males to females was similar (49.9\% females), and the median age of all included patients was 56 years $(I Q R=36.0-71.0)$ ( $\vee$ Table 1$)$.

During 2020, 1,288 examinations related to a suspected or confirmed SARS-CoV-2 infection were carried out, with the first being observed on February 25 ( $\triangleright$ Fig. 2).

\section{All examinations}

Starting in early February 2020, we observed a reduction in examinations, with a further decrease in mid-March and a minimum around early April ( $\triangleright$ Fig. 3,4$)$. Regarding demographic changes, our data shows a slightly increased median age (55 to 57 years) in 2020, as well as higher ratios of men during shutdown compared to the inter- and intra-year control periods ( $\triangleright$ Table $\mathbf{1}$ ).

The total number of radiological examinations during the 35-day shutdown period was 26,967 , yielding an average daily rate of 770.5 examinations $(S D=332.6)$. During the same period in 2018 and 2019, on average 45,819 examinations were performed (1309.1 per day; $S D=523.8$ ), i. e., the shutdown in 2020 led to a decrease of performed examinations of $41.1 \%$ compared to the CTRL. Regarding the PRECOV, PREST, and POST period, a total (mean per day) of 80,240 (1,294.2), 15,506 (1,192.8), and 58,475 $(1,082.9)$ examinations were performed, respectively ( $\vee$ Table 2$)$. 
- Table 1 Number of examinations and patients per year (Jan 1 - June 14, 2020) and demographic information of patients.

- Tab.1 Anzahl der Untersuchungen und Patienten pro Jahr (1. Januar bis 14. Juni 2020) und demografische Informationen.

\begin{tabular}{|c|c|c|c|c|}
\hline & 2018 & 2019 & 2020 & total \\
\hline total number of exams & 205,453 & 210,119 & 181,188 & 596,760 \\
\hline \multicolumn{5}{|l|}{ campus } \\
\hline Mitte & $63,320(30.8 \%)$ & $67,233(32.0 \%)$ & $55,493(30.6 \%)$ & $186,046(31.2 \%)$ \\
\hline Benjamin Franklin & $56,777(27.6 \%)$ & $56,296(26.8 \%)$ & $51,025(28.2 \%)$ & $164,098(27.5 \%)$ \\
\hline Virchow Klinikum & $85,356(41.5 \%)$ & $86,589(41.2 \%)$ & $74,670(41.2 \%)$ & $246,615(41.3 \%)$ \\
\hline total number of patients & 78,902 & 80,644 & 66,919 & 226,465 \\
\hline \multicolumn{5}{|l|}{$\begin{array}{l}\text { number of examinations } \\
\text { per person }\end{array}$} \\
\hline median (IQR) & $2.0(1.0-4.0)$ & $2.0(1.0-4.0)$ & $2.0(1.0-4.0)$ & $2.0(1.0-4.0)$ \\
\hline \multicolumn{5}{|l|}{ sex } \\
\hline women & $39,435(50.0 \%)$ & $40,315(50.0 \%)$ & $33,186(49.6 \%)$ & $112,936(49.9 \%)$ \\
\hline men & 39,251 (49.7\%) & $40,022(49.6 \%)$ & 33,540 (50.1\%) & $112,813(49.8 \%)$ \\
\hline diverse & $2(0.0 \%)$ & $0(0.0 \%)$ & $2(0.0 \%)$ & $4(0.0 \%)$ \\
\hline unknown & $214(0.3 \%)$ & 307 (0.4\%) & $191(0.3 \%)$ & $712(0.3 \%)$ \\
\hline \multicolumn{5}{|l|}{ age } \\
\hline median (IQR) & $55.0(35.0-71.0)$ & $56.0(35.0-70.0)$ & $56.0(37.0-71.0)$ & $56.0(36.0-71.0)$ \\
\hline
\end{tabular}

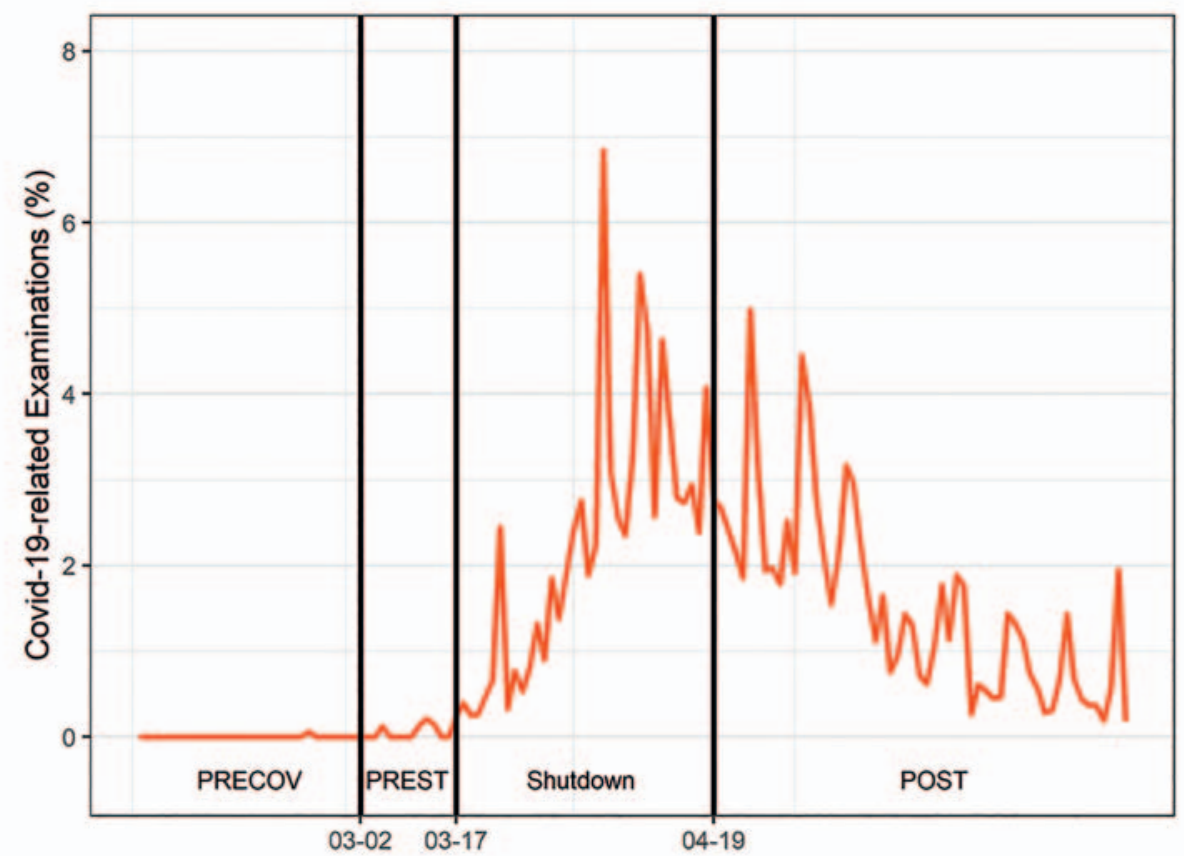

- Fig. 2 Suspected SARS-Cov-2-related radiological examinations. As percentage of all performed examinations. Relevant examinations were specified as "CT Covid-19" or "COVID" was mentioned in the examination risks. (PRECOV: pre-COVID period; PREST: pre-shutdown transition period; POST: post-shutdown transition period).

- Abb.2 Alle mit einer SARS-CoV-2-Infektion assoziierten Untersuchungen. Prozentual zu allen durchgeführten Untersuchungen. Relevante Untersuchungen wurden als „CT COVID-19“ vermerkt oder „COVID“ wurde in den Untersuchungsrisiken erwähnt. PRECOV = Pre-COVID-Zeitraum; PREST = Pre-Shutdown-Übergangszeitraum; POST = Post-Shutdown-Übergangszeitraum. 


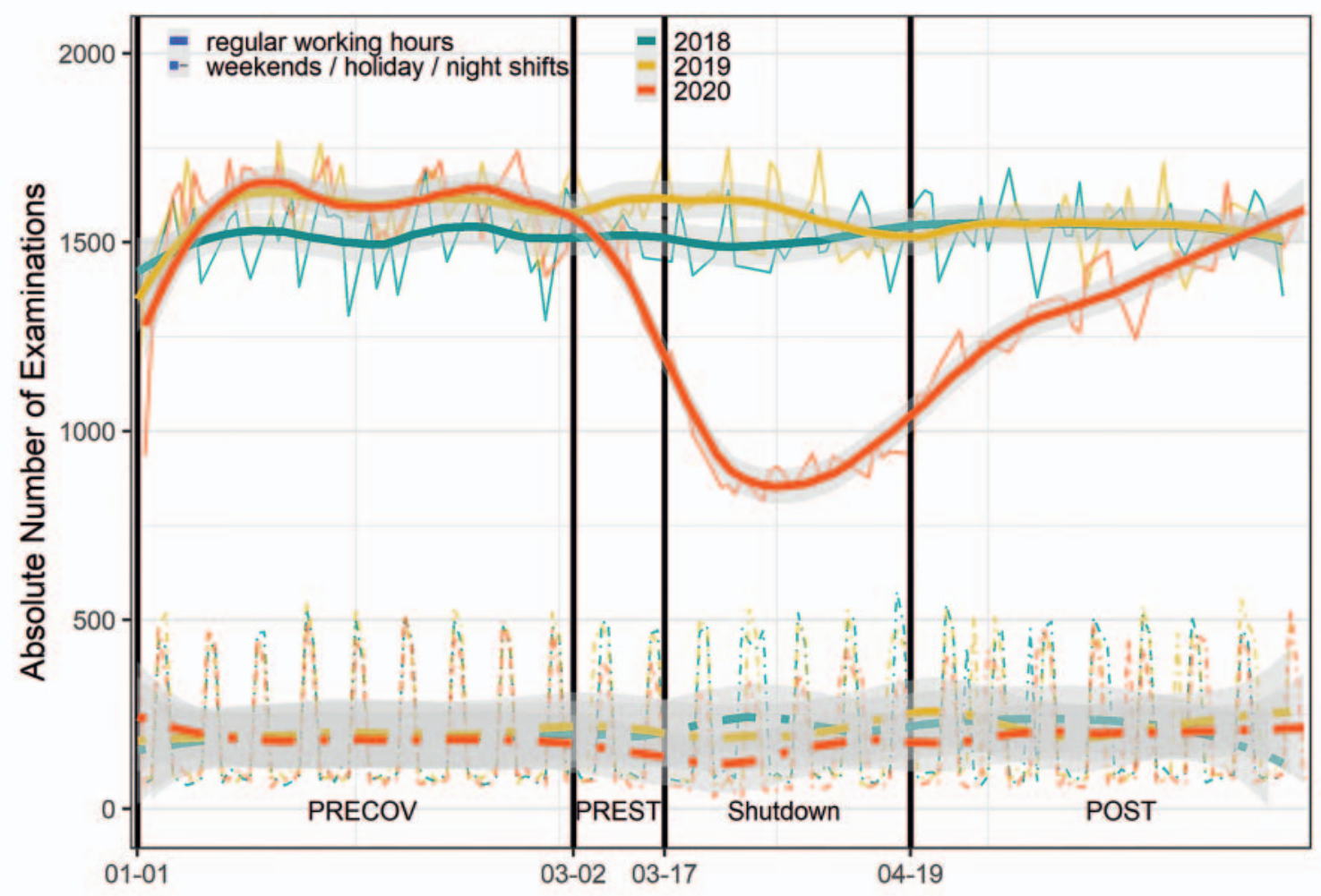

- Fig. 3 Absolute number of examinations by day and with LOESS estimate by regular working hours and night shifts/weekends/holidays (Jan 1 -June 15, 2020). Grey areas mark 95\% Cls. (PRECOV: pre-COVID period; PREST: pre-shutdown transition period; POST: post-shutdown transition period; LOESS: locally weighted scatterplot smoothing; Cl: confidence intervals).

Abb. 3 Absolute Anzahl der Untersuchungen pro Tag und mit LOESS-Schätzung nach regulären Arbeitszeiten und Nachtschichten/Wochenenden/Feiertagen (1. Januar bis 15. Juni 2020). Graue Bereiche markieren $95 \%-K I$. PRECOV = Pre-COVID-Zeitraum; PREST = Pre-ShutdownÜbergangszeitraum; POST = Post-Shutdown-Übergangszeitraum; KI = Konfidenzintervall.

Results from the negative binomial regression similarly show that compared to the CTRL, there were significantly lower rates of daily examinations during the shutdown, as they decreased to about $40 \%$ compared to CTRL (IRR $=0.61 ; 95 \% \mathrm{Cl}: 0.58-0.65)$. In addition, all the intra-year control periods had higher rates than the shutdown (PRECOV: IRR = 1.56, $95 \% \mathrm{Cl}$ : 1.49-1.63; PREST: IRR $=1.41$, $95 \% \mathrm{Cl}: 1.32-1.51$, POST: IRR $=1.3695 \% \mathrm{Cl}: 1.30-$ 1.42).

\section{By Modality}

The most affected radiological modality was sonography with a decrease of $54 \%$ during the shutdown period as compared to CTRL (4,989 vs. 2,305 examinations, - Table 2 ) followed by X-ray (47\%; 15,411 vs. 8,239), and MRI (42\%; 6,977 vs. 4,039). For CT we detected a $25 \%$ decrease in the number of examinations as compared to CTRL $(9,304$ vs. 7,022). It should be noted that when comparing the number of cases in the field of interventional radiology, we observed a $20.8 \%$ decrease compared to baseline numbers for 2019 (467 cases during the shutdown period in 2019 vs. 370 cases in 2020).

\section{By Medical Specialty}

We observed a relevant decrease in radiological examinations for almost all medical specialties during the shutdown compared to the CTRL ( $\triangleright$ Table 2, $\triangleright$ Fig. 5). The most affected medical specialty was trauma and orthopedics, where the rate of daily examinations during shutdown decreased by $60 \%$ compared to CTRL (IRR = 0.43; $95 \% \mathrm{Cl}$ : 0.39-0.48). On average, there were 291.3 examinations per day in $2018 / 19$, and only 114.0 for the same time period in 2020. The next most affected departments were pulmonology, nephrology, and general surgery, where rates were only about half of those in 2018/19.

In the field of emergency medicine, radiological examinations provided for ER patients decreased by $39 \%$ from 8,014 in the CTRL to 4,862 during the shutdown in 2020 (IRR $=0.61$, $95 \% \mathrm{Cl}$ : $0.57-$ 0.64). Examinations provided for stroke units showed a similar trend, as they decreased by $42 \%$ from 313 to 182 (IRR $=0.57$; $95 \% \mathrm{Cl}: 0.48-0.69)$. In contrast, the only medical area not facing such a noticeable decrease in examinations as measured by radiological exams was the ICU $(4,057$ vs. $3,421,16 \%)$, with an IRR of 0.85 (95\% Cl: 0.80-0.89). 


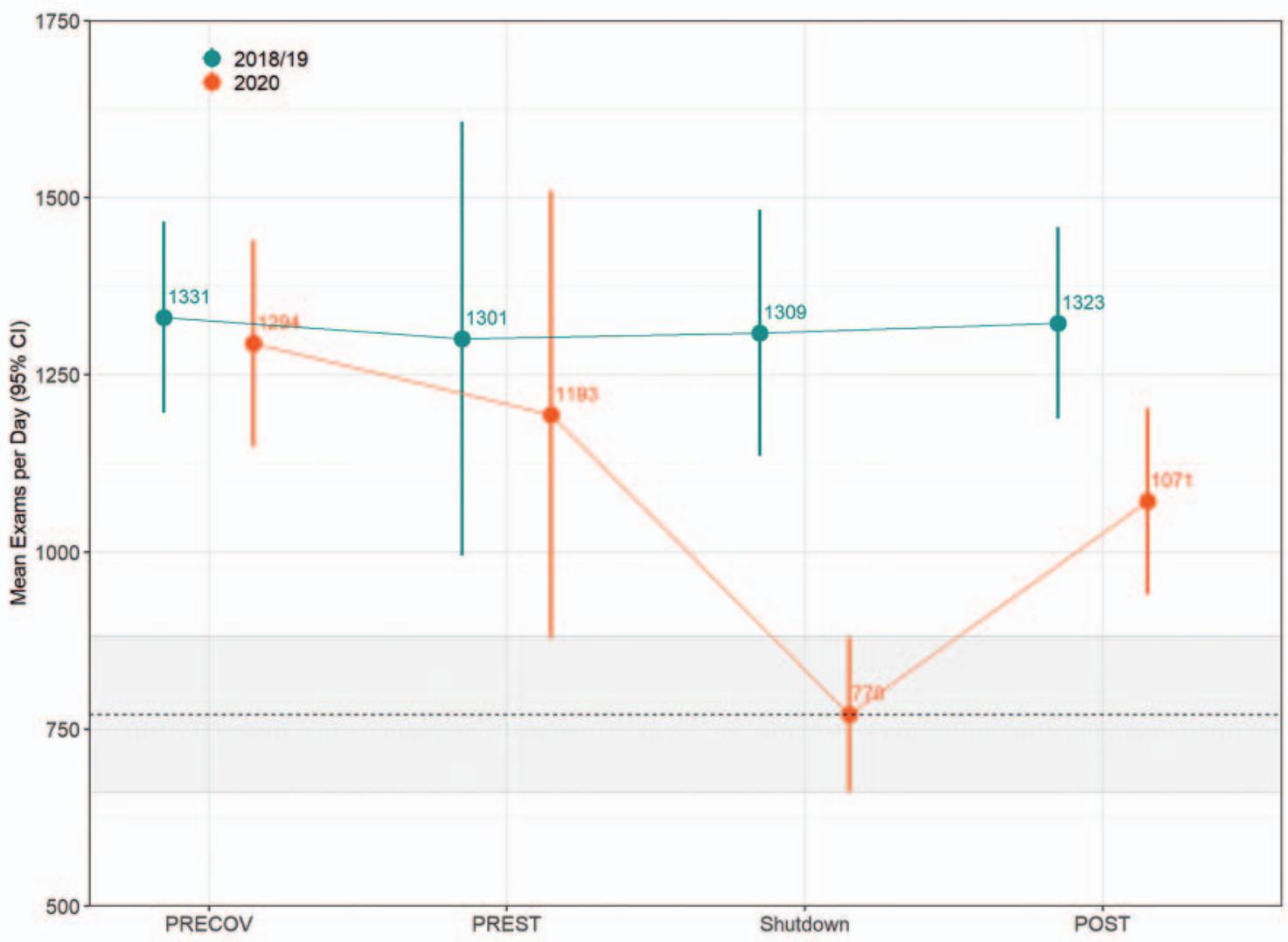

- Fig. 4 Average number of examinations per day for each study period for 2020 and average of 2018/19 (Jan 1 - June 14, 2020), along with $95 \%$ CI (PRECOV: pre-COVID period; PREST: pre-shutdown transition period; POST: post-shutdown transition period; Cl: confidence intervals).

- Abb. 4 Durchschnittliche Untersuchungszahlen pro Tag und in den Studienzeiträumen 2020 und im Durchschnitt 2018/19 (1. Januar bis 14. Juni 2020) zusammen mit 95 \%-KI. PRECOV = Pre-COVID-Zeitraum; PREST = Pre-Shutdown-Übergangszeitraum; POST = Post-Shutdown-Übergangszeitraum; $\mathrm{KI}=$ Konfidenzintervall.

It should be noted that we observed a marked decrease of $58 \%$ for patients referred to radiology from outpatient centers during the shutdown (12,248 vs. 5,093; IRR 0.44; $95 \% \mathrm{Cl}$ : 0.40-0.49, - Table 2). All referrals from in- and outpatient centers were further stratified according to modality and are shown in $>$ Table 3.

\section{By Urgency}

When stratifying cases regarding the time point of acquisition, we observed a relative decrease of $37.8 \%$ of examinations during regular working hours and a decrease of $51.8 \%$ during night shifts, weekends, and holidays ( $\triangleright$ Table 2 ). However, adjusting for the weekday, we did not see relevant differences between these shifts (regular working hours: IRR $=0.60 ; 95 \% \mathrm{Cl}$ : $0.56-0.63$ vs. night shifts, weekends, and holidays: IRR $=0.63 ; 95 \% \mathrm{Cl}$ : $0.59-0.67$,

- Fig. 5).

\section{Future workload}

In the comparison to the pooled benchmark data from 2018/19, we recorded an absolute difference of 34,049 radiological exami- nations in the COVID-19-impacted periods PREST, shutdown, and POST from March 3 through June 14. For examinations provided only in an outpatient setting, we estimate that 12,844 examinations were cancelled (2018/19: 36,379 vs. 2020: $23,535)$, i. e., outpatient examinations reduced by $35.3 \%$ compared to $2018 / 19$. Assuming that all of the 12,844 outpatient examinations not performed during the pandemic and shutdown-impacted period will be carried out within the six following months based on follow-up imaging protocols, we expect an additional 2,141 outpatient examinations per month, resulting in approximately 107 additional cases per workday. Based on data for May and June 2018/19, we would expect on average 491 outpatient examinations to be performed per workday during regular shifts. When extrapolating to the following three months, we estimate an average of 598 radiological examinations in an outpatient setting per day, resulting in an increase of up to $21.8 \%$ as compared to the benchmark workload from 2018/19. 
- Table 2 Absolute number of examinations and average examinations per day within the analyzed time periods stratified by medical specialty.

- Tab.2 Absolute und durchschnittliche Untersuchungszahlen innerhalb der analysierten Zeiträume nach Fachgebieten differenziert.

\begin{tabular}{|c|c|c|c|c|c|c|c|}
\hline & $\begin{array}{l}\text { CTRL } \\
\text { (35 days) }\end{array}$ & $\begin{array}{l}\text { PRECOV } \\
\text { (62 days) }\end{array}$ & $\begin{array}{l}\text { PREST } \\
\text { (13 days) }\end{array}$ & $\begin{array}{l}\text { shutdown } \\
\text { ( } 35 \text { days) }\end{array}$ & $\begin{array}{l}\text { POST } \\
\text { (54 days) }\end{array}$ & \multicolumn{2}{|c|}{$\begin{array}{l}\text { shutdown vs. CTRL } \\
\text { absolute and relative } \\
\text { decrease }\end{array}$} \\
\hline $\begin{array}{l}\text { total number of exams } \\
\text { (mean per day) }\end{array}$ & $45,819(1,309.1)$ & $80,240(1,294.2)$ & $15,506(1,192.8)$ & 26,967 (770.5) & $58,475(1,082.9)$ & $-18,852$ & $41.1 \%$ \\
\hline \multicolumn{8}{|l|}{$\begin{array}{l}\text { time point of } \\
\text { acquisition }\end{array}$} \\
\hline regular working hours & 34,767 (993.3) & $68,471(1,104.4)$ & $13,411(1,031.6)$ & $21,642(618.3)$ & 48,361 (895.6) & $-13,124.5$ & $37.8 \%$ \\
\hline $\begin{array}{l}\text { weekends/holidays/ } \\
\text { night shifts }\end{array}$ & $11,053(315.8)$ & $11,769(189.8)$ & 2,095 (161.2) & $5,325(152.1)$ & $10,114(187.3)$ & $-5,727.5$ & $51.8 \%$ \\
\hline \multicolumn{8}{|l|}{$\begin{array}{l}\text { emergency rooms and } \\
\text { outpatient centers }\end{array}$} \\
\hline outpatient centers & 12,248 (349.9) & 21,715 (350.2) & $4,180(321.5)$ & $5,093(145.5)$ & $14,262(264.1)$ & $-7,155$ & $58.4 \%$ \\
\hline ER & $8,014(229.0)$ & $13,165(212.3)$ & $2,122(163.2)$ & 4,862 (138.9) & $9,719(180.0)$ & $-3,152$ & $39.3 \%$ \\
\hline \multicolumn{8}{|l|}{ referring wards } \\
\hline ICUs & 4,057 (115.9) & 6,689 (107.9) & 1,403 (107.9) & $3,421(97.7)$ & $5,613(103.9)$ & -636 & $15.7 \%$ \\
\hline cardiology & $730(20.8)$ & $962(15.5)$ & $190(14.6)$ & $400(11.4)$ & $819(15.2)$ & -330 & $45.2 \%$ \\
\hline pulmonology & $735(21.0)$ & $1,083(17.5)$ & $184(14.2)$ & $362(10.3)$ & $821(15.2)$ & -373 & $50.7 \%$ \\
\hline nephrology & $1,413(40.4)$ & $2,655(42.8)$ & $506(38.9)$ & $706(20.2)$ & $1,562(28.9)$ & -707 & $50.0 \%$ \\
\hline gastroenterology & $1,406(40.2)$ & $2,408(38.8)$ & $492(37.8)$ & $805(23.0)$ & $1,781(33.0)$ & -602 & $42.7 \%$ \\
\hline $\begin{array}{l}\text { neurology w/o stroke } \\
\text { units }\end{array}$ & $1,468(41.9)$ & $2,289(36.9)$ & $440(33.8)$ & $804(23.0)$ & $1,835(34.0)$ & -664 & $45.2 \%$ \\
\hline stroke units & $313(8.9)$ & $422(6.8)$ & $104(8.0)$ & $182(5.2)$ & $411(7.6)$ & -131 & $41.9 \%$ \\
\hline pediatrics & $2,014(57.5)$ & $3,348(54.0)$ & $622(47.8)$ & $1,164(33.3)$ & $2,553(47.3)$ & -850 & $42.2 \%$ \\
\hline oncology & $2,207(63.1)$ & $4,266(68.8)$ & $813(62.5)$ & $1,645(47.0)$ & $3,221(59.6)$ & -562 & $25.5 \%$ \\
\hline general surgery & $2,618(74.8)$ & $4,107(66.2)$ & $783(60.2)$ & $1,348(38.5)$ & $2,758(51.1)$ & $-1,270$ & $48.5 \%$ \\
\hline trauma and orthopedics & $6,701(291.3)$ & 12,682 (294.9) & $2,379(264.3)$ & $2,621(114.0)$ & $8,427(936.3)$ & $-4,080$ & $60.1 \%$ \\
\hline \multicolumn{8}{|l|}{ modality } \\
\hline sonography & $4,989(142.5)$ & $7,580(122.3)$ & $1,459(112.2)$ & $2,305(65.9)$ & $5,739(106.3)$ & $-2,684$ & $53.8 \%$ \\
\hline X-ray & $15,411(440.3)$ & $24,429(394.0)$ & $4,723(363.3)$ & $8,239(235.4)$ & $17,687(327.5)$ & $-7,172$ & $46.5 \%$ \\
\hline MRI & 6,977 (199.3) & $13,276(214.1)$ & $2,629(202.2)$ & $4,039(115.4)$ & $9,590(177.6)$ & $-2,938$ & $42.1 \%$ \\
\hline CT & $9,304(265.8)$ & $17,541(282.9)$ & $3,338(256.8)$ & $7,022(200.6)$ & $14,057(260.3)$ & $-2,282$ & $24.5 \%$ \\
\hline other & $9,140(261.1)$ & 17,414 (280.9) & $3,357(258.2)$ & $5,362(153.2)$ & $11,402(211.1)$ & $-3,78$ & $41.3 \%$ \\
\hline
\end{tabular}

CTRL: control period 2018/19; PRECOV: pre-COVID period; PREST: pre-shutdown transition period; POST: post-shutdown period; ER: emergency rooms; ICU: intensive care units.

\section{Discussion}

In our study we demonstrated (i) a significant decrease in medical care as measured by radiological examinations during the 35-day shutdown period in comparison to intra- and inter-year control periods. When stratifying our data regarding medical disciplines, we could show that (ii) almost all medical specialties faced a significant decrease in patient volume. Finally, (iii) the number of overall cases significantly increased again during POST and ex- ceeds the average workload, thereby putting further pressure on the healthcare system.

Multiple studies have shown a similar decrease in patient care during the COVID-19 pandemic, including surgical disciplines [18-21], internal medicine[11], and emergency departments [10], confirming our large-scale results with absolute patient numbers. While a decrease in cases in emergency departments might be directly related to nationwide shutdown laws (e. g., due to fewer traffic accidents), changes in stroke-related admissions cannot be explained on a patho-physiological basis, especially 


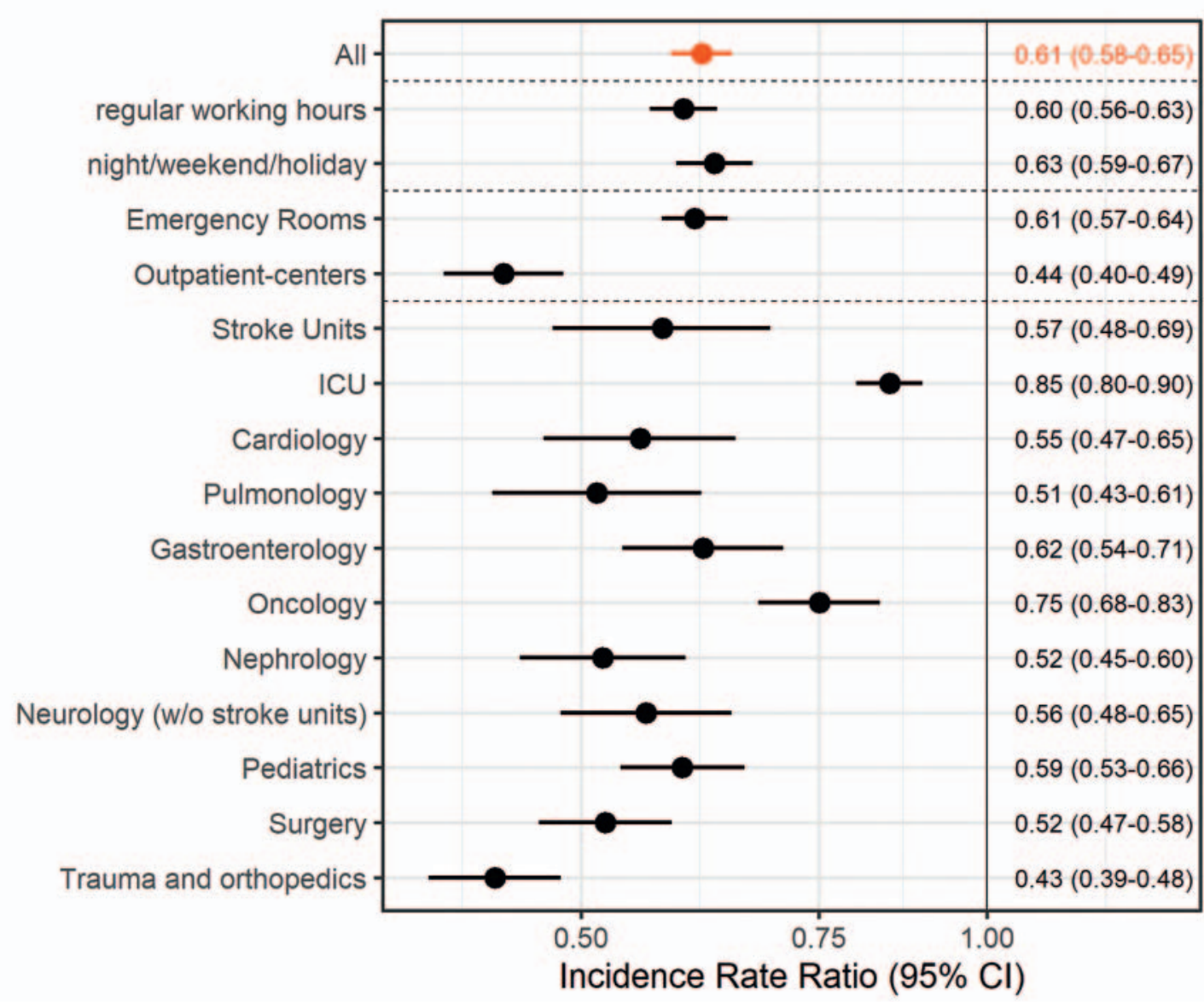

- Fig. 5 Incidence rate ratios for the comparison of shutdown vs. control 2018/19 by medical specialty, along with $95 \% \mathrm{Cl}$ derived from negative binominal regression (ER: emergency rooms; ICU: intensive care units; Cl: confidence intervals).

- Abb.5 Vergleich von Shutdown vs. Control 2018/19 nach medizinischen Fachgebieten zusammen mit 95\%-KI, abgeleitet aus der negativbinominalen Regression. ER = Notaufnahme; ICU = Intensivstation; KI = Konfidenzintervall.

since viral pneumonia is associated with an increased stroke risk [22]. Our results are in accordance with recently published data from North America, where the authors found a decrease in acute stroke imaging during the SARS-CoV-2 outbreak, supporting the hypothesis that fewer stroke patients have sought medical help during the COVID-19 pandemic [15].

Due to an increased need for ICU capacity for severe cases of SARS-CoV-2 infections, ICUs have been notably impacted by the COVID-19 pandemic and are therefore at the center of attention [23]. In contrast to all other disciplines, radiological examinations provided for ICUs differed the least during the shutdown compared to the CTRL. This might reflect an increased workload related to COVID-19 patients, reducing the overall effect of the decreased quantity of medical care provided.

Interestingly, basic examinations such as sonography (-53.8\%) and X-ray (46.5\%) were effected more heavily than MRI (42.1\%) and CT examinations (24.5\%). Our data indicates that the decrease is mainly due to reduced outpatient volumes, i. e., from orthopedics and trauma surgery where $\mathrm{X}$-ray examinations are the main imaging modality. During the study period, radiological examina- tions for oncological patients were reduced by $26 \%$ compared to the CTRL. In this context we already saw a significant increase in the quantity of patient care during the POST period as compared to the shutdown period, even exceeding the benchmark levels

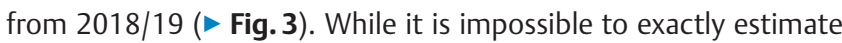
future workload, we approximate an additional workload of up to $22 \%$ for outpatient examinations for the upcoming six months, based on the benchmark data from 2018/19 [24, 25]. Especially patients with chronic and oncological diseases who are highly dependent on follow-up care need to stay in the focus of medical attention in this regard [26, 27]. Data from past natural disasters showed significantly lower overall survival rates, especially for these specific patient groups, if neglected [28-30]. Since natural disasters are locally limited and are temporary, the implications for high-risk groups could be even worse in the case of a global pandemic such as COVID-19. We therefore recommend a prioritization of patients with chronic and oncological diseases during the months following pandemic-related shutdowns, to avoid unpredictable consequences for the course of disease in individual patients and healthcare systems as a whole [24, 25, 28, 31]. 
- Table 3 Absolute number of examinations within the analyzed time periods stratified by modality and regarding in- or outpatient referral.

> Tab.3 Absolute Untersuchungszahlen innerhalb der analysierten Zeiträume nach Modalität und ambulanter oder stationärer Überweisung differenziert.

\begin{tabular}{|c|c|c|c|c|c|c|c|c|}
\hline \multirow[b]{2}{*}{ inpatients } & \multirow{2}{*}{$\begin{array}{l}\text { modality } \\
\text { CT }\end{array}$} & \multirow{2}{*}{$\begin{array}{l}\text { CTRL } \\
\text { (35 days) } \\
7,428.5 \\
\end{array}$} & \multirow{2}{*}{$\begin{array}{l}\text { PRECOV } \\
\text { (62 days) } \\
13,944\end{array}$} & \multirow{2}{*}{$\begin{array}{l}\text { PREST } \\
\text { (13 days) } \\
2,635\end{array}$} & \multirow{2}{*}{$\begin{array}{c}\text { shutdown } \\
\text { (35 days) } \\
5,878\end{array}$} & \multirow{2}{*}{$\begin{array}{l}\text { POST } \\
\text { (54 days) } \\
11,456\end{array}$} & \multicolumn{2}{|c|}{$\begin{array}{l}\text { shutdown vs. CTRL } \\
\text { absolute and relative } \\
\text { decrease }\end{array}$} \\
\hline & & & & & & & $-1,551$ & $-20.9 \%$ \\
\hline & MRI & $4,086.5$ & 7,974 & 1,647 & 2,609 & 5,847 & $-1,478$ & $-36.2 \%$ \\
\hline & other & $6,726.5$ & 12,789 & 2,451 & 4,414 & 8,893 & $-2,313$ & $-34.4 \%$ \\
\hline & X-ray & 12,299 & 19,114 & 3,747 & 7,270 & 14,436 & $-5,029$ & $-40.9 \%$ \\
\hline & sonography & 3,033 & 4,704 & 846 & 1,703 & 3,581 & $-1,330$ & $-43.9 \%$ \\
\hline \multirow[t]{5}{*}{ outpatients } & CT & 1,876 & 3,597 & 703 & 1,144 & 2,601 & -732 & $-39.0 \%$ \\
\hline & MRI & 2,891 & 5,302 & 982 & 1,430 & 3,743 & $-1,461$ & $-50.5 \%$ \\
\hline & other & 2,413 & 4,625 & 906 & 948 & 2,509 & $-1,465$ & $-60.7 \%$ \\
\hline & X-ray & $3,112.5$ & 5,315 & 976 & 969 & 3,251 & $-2,144$ & $-68.9 \%$ \\
\hline & sonography & 1,956 & 2,876 & 613 & 602 & 2,158 & $-1,354$ & $-69.2 \%$ \\
\hline
\end{tabular}

As the second wave of the pandemic continues, the redistribution of medical resources and transfer of COVID-19 patients to less impacted areas are being broadly debated on national and supra-national levels. Our comprehensive results show in detail the extent to which individual medical specialties have been affected by the pandemic as well as possible free capacity. Hence, this study not only provides important data for an effective redistribution of resources within hospitals but may support informed decision-making in national healthcare systems and supra-national institutions.

This study has several limitations. Firstly, our study is limited by its retrospective character, using only data from a single university hospital in Germany. This might have caused a selection bias of the patient cohort. However, the Charité Berlin consists of three maximum-care hospitals located throughout the city, each as big as an average university hospital. Second, the course of the COVID-19 pandemic in Germany might not be comparable to other countries. Therefore, conclusions might have to be interpreted with caution. Yet, since mid-March almost all developed countries worldwide have implemented similar shutdown or even lockdown laws in order to contain the COVID-19 pandemic. With the second wave in full swing in Western Europe, we believe that evaluating data from Germany is in fact a strength since it might indicate future developments in similarly affected countries. Lastly, in this study we used radiological examinations as a surrogate marker for medical care and the collected data might not correctly reflect actual workload levels. However, to our knowledge, this is the largest radiological data analysis with respect to effects of the COVID-19 pandemic and its related measures on healthcare. With over half a million examinations assessed, we strongly believe that our analysis is robust and is a reliable marker for the quantity of medical care provided.

In summary, we conclude that the first wave of the COVID-19 pandemic and related shutdown measures caused a marked de- crease in the overall medical care provided as measured by radiological examinations. Several core medical specialties showed a significant reduction in case numbers. We could furthermore estimate that a considerable portion of the postponed medical care has to be compensated for, thus putting additional pressure on already strained health care infrastructures while the second wave is underway.

In memory of a lost mentor: Authors F. N. F. and T. M. are fellows of the BIH Charité Clinician Scientist Program. The program was initiated and led by Prof. Dr. Duska Dragun to enable resident physicians to pursue careers in academic medicine and research. With great sadness we have received the news that Prof. Dragun passed away on December $28^{\text {th }}$ of 2020 . This publication is dedicated to her as a mentor, friend, role model and stellar scientist.

\section{Conflict of Interest}

The authors declare that they have no conflict of interest.

\section{References}

[1] Zhou P, Yang XL, Wang XG et al. A pneumonia outbreak associated with a new coronavirus of probable bat origin. Nature 2020; 579: 270-273

[2] WHO Director-General's opening remarks at the media briefing on COVID-19 - 11 March. 2020 https://www.who.int [press release]

[3] Baddour K, Kudrick LD, Neopaney A et al. Potential impact of the COVID-19 pandemic on financial toxicity in cancer survivors. Head Neck 2020. doi: $10.1002 /$ hed. 26187

[4] Nicola M, Alsafi Z, Sohrabi C et al. The socio-economic implications of the coronavirus pandemic (COVID-19): A review. Int J Surg 2020; 78: 185193

[5] Coronavirus Disease 2019 (COVID-19) Daily Situation Report of the Robert Koch Institute 04/03/2020 (english) [press release]. Berlin, Germany, 2020 
[6] Telephone conference between the Fedaral Chancellor of Germany, Federal Government of Germany and the heads of State Governments, April $30^{\text {th }}, 2020$ (in german). Berlin, Germany, 2020 https://www.bundesregierung.de [press release]

[7] Federal law for the protection of the public in the event of epidemic situations. BGBI. I S. 580 27. März 2020 (in german). 2020

[8] Garcia S, Albaghdadi MS, Meraj PM et al. Reduction in ST-Segment Elevation Cardiac Catheterization Laboratory Activations in the United States during COVID-19 Pandemic. J Am Coll Cardiol 2020. doi:10.1016/ j.jacc.2020.04.011

[9] Angelico R, Trapani S, Manzia TM et al. The COVID-19 outbreak in Italy: Initial implications for organ transplantation programs. Am J Transplant 2020. doi:10.1111/ajt.15904

[10] Christey G, Amey J, Campbell A et al. Variation in volumes and characteristics of trauma patients admitted to a level one trauma centre during national level 4 lockdown for COVID-19 in New Zealand. N Z Med J 2020; 133: $81-88$

[11] De Filippo O, D’Ascenzo F, Angelini F et al. Reduced Rate of Hospital Admissions for ACS during Covid-19 Outbreak in Northern Italy. N Engl J Med 2020. doi:10.1056/NEJMc2009166

[12] Holmes JL, Brake S, Docherty M et al. Emergency ambulance services for heart attack and stroke during UK's COVID-19 lockdown. Lancet 2020. doi:10.1016/S0140-6736(20)31031-X

[13] Barnett ML, Mehrotra A, Landon BE. Covid-19 and the Upcoming Financial Crisis in Health Care. Catalyst non-issue content 2020; 1 : doi:10.1056/CAT.20.0153

[14] Ai T, Yang Z, Hou $\mathrm{H}$ et al. Correlation of Chest CT and RT-PCR Testing in Coronavirus Disease 2019 (COVID-19) in China: A Report of 1014 Cases. Radiology 2020: 200642

[15] Kansagra AP, Goyal MS, Hamilton S et al. Collateral Effect of Covid-19 on Stroke Evaluation in the United States. N Engl J Med 2020. doi:10.1056/ NEJMc2014816

[16] R Core Team. A language and environment for statistical computing. Vienna: R Foundation for Statistical Computing. 2019

[17] Wickham H, Averick M, Bryan J et al. Welcome to the Tidyverse. Journal of Open Source Software 2019; 4: 1686

[18] Oderda M, Roupret M, Marra G et al. The Impact of COVID-19 Outbreak on Uro-oncological Practice Across Europe: Which Burden of Activity Are We Facing Ahead? Eur Urol 2020. doi:10.1016/j.eururo.2020.04.036
[19] Wexner SD, Cortes-Guiral D, Gilshtein H et al. COVID-19: Impact on Colorectal Surgery. Colorectal Dis 2020. doi:10.1111/codi.15112

[20] Liebensteiner MC, Khosravi I, Hirschmann MT et al. Massive cutback in orthopaedic healthcare services due to the COVID-19 pandemic. Knee Surg Sports Traumatol Arthrosc 2020. doi:10.1007/s00167-020-06032-2

[21] Maggi U, De Carlis L, Yiu D et al. The impact of the COVID-19 outbreak on Liver Transplantation programmes in Northern Italy. Am J Transplant 2020. doi:10.1111/ajt.15948

[22] Warren-Gash C, Blackburn R, Whitaker $\mathrm{H}$ et al. Laboratory-confirmed respiratory infections as triggers for acute myocardial infarction and stroke: a self-controlled case series analysis of national linked datasets from Scotland. Eur Respir J 2018; 51: doi:10.1183/13993003.01794-2017

[23] Phua J, Weng L, Ling L et al. Intensive care management of coronavirus disease 2019 (COVID-19): challenges and recommendations. Lancet Respir Med 2020. doi:10.1016/S2213-2600(20)30161-2

[24] Sugiyama T, Hirose T, Hosaka T et al. Effectiveness of intensive follow-up after response in patients with small cell lung cancer. Lung Cancer 2008; 59: 255-261

[25] Renehan AG, Egger M, Saunders MP et al. Impact on survival of intensive follow up after curative resection for colorectal cancer: systematic review and meta-analysis of randomised trials. BM] 2002; 324: 813

[26] Liang W, Guan W, Chen R et al. Cancer patients in SARS-CoV-2 infection: a nationwide analysis in China. Lancet Oncol 2020; 21: 335-337

[27] The Lancet O. COVID-19: global consequences for oncology. Lancet Oncol 2020; 21: 467

[28] Nogueira LM, Sahar L, Efstathiou JA et al. Association Between Declared Hurricane Disasters and Survival of Patients With Lung Cancer Undergoing Radiation Treatment. JAMA 2019; 322: 269-271

[29] Man RX, Lack DA, Wyatt CE et al. The effect of natural disasters on cancer care: a systematic review. Lancet Oncol 2018; 19: e482-e499

[30] Moscona JC, Peters MN, Maini R et al. The Incidence, Risk Factors, and Chronobiology of Acute Myocardial Infarction Ten Years After Hurricane Katrina. Disaster Med Public Health Prep 2019; 13: 217-222

[31] O’Connor JP, Aboagye EO, Adams JE et al. Imaging biomarker roadmap for cancer studies. Nat Rev Clin Oncol 2017; 14: 169-186 